\title{
From Re-viewers to Me-viewers: The \#Bookstagram Review Sphere on Instagram and the Uses of the Perceived Platform and Genre Affordances
}

This study looks at the emerging forms of reviewing cultural products by investigating \#bookreviews on Instagram. The multiple-case study focuses on characteristics of bookreview posts in global and national contexts. First, the global community is outlined, with the help of quantitative data ( $N=163,269$ entries). Second, a local book-reviewing community ( $N=645$ entries) is studied, with a thematic analysis of platform and genre affordances. Instagram-native formats identified include textual reviews, metacoverage of reviews, video reviews, reviews with visual effects and facilitated reviews. The findings have implications for the conceptualisation of user-generated reviewing as part of cultural critique, which requires the incorporation of the consumption/prosumption paradigm into the understandings of cultural intermediation.

Keywords: Review, Vernacular Reviewing, Book Cultures, Reading, Cultural Engagement, Instagram, Bookstagram

\section{Introduction}

Re-examining a cultural product once it has been made available to the public, with the intention of judging whether it is good or bad or to 'criticize' it - from the Greek verb krinein, 'to decide'- has long constituted a central element in the formation of audience's opinions, tastes and lifestyles (Wright 2015). However, the power to address cultural products in the public sphere has never been so much in the hands of cultural consumers and citizens as it is now. Traditionally, the institution of criticism allowed only a limited group of cultural connoisseurs selected and legitimized by media and cultural institutions to make public and informed assessments to educate audiences, based on their alleged superiority in the refined taste (Hohendahl 1982, Titchener 1998, Blank 2007). The recent participatory turn of cultural analysis and theory has directed increased scholarly attention to non-institutional cultural voices (Jenkins 2006, Bruns 2008), simultaneously giving rise to notions of the end of the institutionalized cultural or arts criticism as a closed form of production, implying that the post-industrial cultural criticism is now open to everyone (Kammer 2015, McWhirther 2016). This calls for studying the versatile ways of how new cultural products are presented, assessed and judged in a wide repertoire of social media.

Discussions concerning the cultural 'produsage' (Bruns 2008) or 'prosumption' (Toffler 1980), in which ordinary users or consumers not only receive, but also actively accomplish an input of their own, have been dedicated to review blogs (Kammer 2015, Steiner 2008, 2010) and specific amateur review platforms (Verboord 2010, Frey and Sayad 2015). A predominant question in studying the new forms of reviewing is how the traditional or classical critical literary genres have been adapted to new digital platforms (Domsch 2009, Miller and Shepherd 2009). Also, social influencers or promotional reviewers have been studied (Abidin 2017, Schwemmer and Ziewiecki 2018, AUTHOR, 2019, forthcoming). Less attention, though, has been paid to the online-native or emic understanding of the genre of reviewing on social networking sites and how this transforms the audiences' - not the least 
the young and future ones - understandings of review and reviewing; instead, social networking sites have been more often considered as a space for cultural discussion, for example, book discussion, that is a field that is considerably wider than book reviewing (Boot 2011, Grafton 2010). More generally, with an increasing number of 'reviews' on video games or plays, technology gadgets, software, toys, cosmetics, food, and a variety of other products, there seems to a re-configuration in the vernacular domain of communication concerning the very meanings of the 'review' (e.g. AUTHOR 2018, 2019). General social networking sites such as YouTube and Instagram differ from publishing platforms dedicated for reviewing such as Rotten Tomatoes or IMDB in that they, as multi-purpose platforms, do not compel users to follow a certain type of review or genre, or position the user to one single producer role. Instead, the understandings of the genre emerge and evolve within the community through negotiations with platform policies and technologies available, and through sociocultural negotiations with other users to create standards and norms of quality, concerning both the performance and the product. The concept of the 'review' genre is thus more open, and more subject to new openings imposed and encouraged by the techno-social environment. The object of interest is located at the intersection of media studies and cultural theory, and for referring to the individualized cultural production I will apply the term public cultural engagement instead of participation because the former more appropriately captures the individual's prosumption agency as an initiator of cultural and communicative processes, not just placing him or her to a role of a participant of a pre-initiated process (see also Curran and Morley 2006, Couldry et al. 2010, Bolin 2011). My starting point is that the vernacular reviewers are 'owners' of self-initiated processes that might not be there before they invent or re-invent them, even if they are often engaged in participatory processes such as book challenges or viral campaigns.

Related to this question of the transformation of reviews and reviewing, my major concern in this article is how this occurs in a platform-specific way by making use of perceived affordances of the platform and the genre, with an example of book reading. Among the younger major social networking sites, the visual medium Instagram, launched in 2010, has become one of the most prolific social platforms for readers to connect with books. Instagram has rapidly developed into a social media platform that is more popular than Twitter, Snapchat or Pinterest, with 800 million active users and almost 40 billion photos posted (WordStream 2017). Designed for mobile media, it appeals in particular to 18-29 year olds and, therefore, offers insights into reviews and reviewing among younger audiences. Instagram is used multiple times per day by 71 per cent of Americans between the ages of 18 and 24 (Smith and Anderson 2018). The popularity of the subject of books on Instagram is reflected in frequently used hashtags such as \#book, which at the end of 2018 had about 36 million entries, and \#bookstagram, which had about 26 million entries. According to Faroukh Naseem, the Bookstagrammer of the Year at the London Book Fair 2018, Bookstagram is 'an online space on Instagram where people post pictures and videos of books and talk all things bookish' (Naseem 2018). As part of these 'bookish' discourses and practices, users are also reviewing books. The hashtag \#bookreview was found by manual search in approximately 830,000 entries.

In this article, I will analyse public book review Instagram posts in order to explore how the dedicated vernacular reviewer accounts utilise the perceived visual, audiovisual and textual affordances of the platform and of the review genre to address books. This will increase understanding of how book-reviewing cultures manifest among the ordinary users online, or how these users express cultural engagement online. I will start by briefly outlining the phenomenon of vernacular reviewing. 


\section{Vernacular reviewing}

'Review' refers to a form of presentation in which an author creates, motivates and delivers an informed opinion about a cultural object to the public (Blank 2007). Reviews are 'public summaries and evaluations that assist readers to be more knowledgeable in their choice, understanding, or appreciation of products or performances' and answer the questions 'what is it?' and 'is it any good?' (Blank 2007: 7). A review is thus 'a report with opinion', characterized by a journalistic 'who-did-what-when approach' and typically written for a wider audience than is criticism (Titchener 1998). Reviews are usually published on a regular basis by someone who intends to establish a profile as an evaluator of new cultural products.

The institutional and non-institutional forms of reviewing require a separate theoretical inquiry and it is not in the scope of this article that intends to focus on a platform-specific form of book reviews produced by ordinary uses, defined as a form of vernacular or noninstitutionalized reviewing (see AUTHOR 2019, forthcoming). In its institutional form, review as a genre has been applied in journalism across different media, for example newspapers - where it has had its strongest presence, culture magazines, television and radio. The institutional journalistic genre of review has been produced by persons specifically recruited by media organisations and typically legitimated by the communities of production to which the reviews belong. Institutional reviewing shows a structure of power constructed from the top-down, which leaves less voice to ordinary cultural consumers. Institutional professional reviewing can be characterized to a great extent as an organisation-led meritocracy, which through a careful selection of recruited reviewers legitimizes a limited number of voices, positioning the audiences exclusively as recipients to be informed and educated. As discussed by Verboord (2010), participatory practices add to the legitimacy of vernacular reviewers, while they decrease that of professional, institutionalized reviewers.

In online communication and especially in its vernacular form, the review has to be distinguished from users' general reactions upon topical issues or releases of new cultural products. These reactions are produced in various types of genres and can more generally be gathered under the umbrella term of online discussion or, in the context of literature and book culture, 'book discussion' (Boot 2011) or 'online writing' (Steiner 2010). The review, however, implies an explicit ambition to articulate the worth of a cultural object, whether this is an aesthetic work such as book, film or piece of music, or a service or experience, such as a restaurant or hotel visit (Blank 2007, Orlik 2016). As such, the review is based on a conscious act of choosing to review an object, and marks a stand-alone presentation that can be received without having to get acquainted with the contexts, even if this presentation may refer to broader processes or be part of collective processes.

To emphasize the bottop-up or lay approach, reviewers in the vernacular domain have been characterized as 'amateurs', 'customers', 'professional amateurs' ('pro-ams'), 'everyday amateur experts' (Kristensen and From 2017, Kammer 2015, Steiner 2010, Leadbeater and Miller 2004). In the field of literature, non-institutionalized reviewers have been called - if not simply 'readers', 'bloggers', 'vloggers', 'users' or 'lay persons' - 'reader reviewers' (Steiner 2008) or 'public readers' (Grafton 2010). Verboord (2010) distinguishes between reviewers (but uses the term 'critic') of varying degrees of institutionalisation and identifies 
three categories: 'expert critics', 'Internet critics' and 'peer critics'. It is thus evident that the group of reviewers is heterogeneous, drawing on different grades of cultural and media capital. In addition, the production roles are not static as they used to be in the gate-keeper system of the traditional institutionalized criticism. Typically, review platforms provide users with pre-assigned amateur roles, while the content produced by users in multi-purpose networking sites is self-identified reviewer content. The institutionalized and noninstitutionalized amateurs are situated on a sliding scale. The vernacular review sphere allows producers with a wide degree of expertise, ranging from professionals in a field with careful selectivity of products to set under review (AUTHOR 2019, forthcoming) to lay persons presenting products that they have been able to access (AUTHOR 2018). From different subject positions and different types of agency, ranging, again, from relatively autonomous producers with high integrity to more heterogeneous positions of commercially partnered social influencers, they approach cultural products from different directions and are free to define and discover the possibilities of the review genre in ways that best suit their communication strategies. The roles of a 'professional' are mimicked by amateurs and the other way around (Nicoll and Nansen 2018), to convincingly produce authenticity, or, as Abidin (2017) calls it, 'calibrated amateurism'.

As said, in contrast to its institutional counterparts, vernacular reviewing is constituted from bottom up and is far more dispersed and less structured as a social phenomenon. It belongs to the character of vernacularity that it is not centrally defined or regulated by any central or intermediary organisation but grows from within online communities. It is to a high degree influenced by, and needs to be understood by, the platform specificity and how the community of users identifies and makes use of the platforms central features. Sociocultural theories of online genres (see e.g. Giltrow and Stein 2009) put emphasis on the forming processes how genres are collaboratively developed as situated responses to fulfil certain functions. Genres are patterned structures of social action that are socially agreed upon (Giltrow and Stein 2009), identifiable by certain conventions that audiences come to recognize through regular exposure. In the conjunction of the platform use and genre formation, it is the perceived affordances (Norman 1999) of the platform and of the genre that play a central role. According to Norman (1999, see also Gibson 1979), an affordance is the design aspect of an object, in this context either of the visual app Instagram or the social convention of the review genre, which suggests how this object should be used. To be effectively used, an affordance has to be perceived, i.e. identified and transformed into a functional feature.

On Instagram, central affordances for producing a post, which is the unit of analysis in this article, are the possibilities and restrictions related to using image, written text, user interaction and cross-platform communication. User reviewers have to make a choice between still images and videos, select the way of visualisation, make more or less informed choices regarding the text content, structure and length, and choose how to use Instagram posts as part of their communication in social media in general. As for the review genre, the creation of the critical authority is paramount. By positioning him- or herself consciously as a reviewer, or constituting a reviewer's voice that is eventually legitimized, rejected or ignored by the audiences, the reviewer in some way produces itself through review texts. Adapting a reviewer's role is thus a reciprocal act of self-proclaiming oneself to be a reviewer while possibly gaining the confirmation and legitimacy by the audiences. In the case of online audiences, the legitimisation occurs through the accumulation of followers and user feedback (likes, commentaries, re-posts). 
This said, authors of reviews are making use of the perceived affordances of Instagram's interface and the patterns of the review genre, and by doing this, they are sort of 'reinventing' the review genre in the specific online environment of Instagram. By examining how the Instagram review or the 'IG review' (\#igreview) is conceived and applied we can cast light on the emerging phenomenon of vernacular reviewing, which is developing alongside the institutional (professional) and amateur (platforms for pre-assigned 'amateur' or 'customer' reviewing, as at Amazon) forms of reviewing.

\section{Research objective}

The objective of this study is to identify and describe the functions and characteristics of Instagram posts that are labelled as reviews, asking what Instagram reviews are and how they are constituted by making use of the affordances of the media platform, on one hand, and the genre, on the other. The study traces the uses of perceived platform and genre affordances in order to better understand the Instagram book review as an online-native genre representing platform-specific vernacular content creation. The object of inquiry in this study is original Insta- or Bookstagrammers, that is users with established Instagram presence and creators of more or less original content to Instagram instead of solely referring to others' output.

A thematic analysis of the uses of perceived affordances explores how the Instagram review has been constituted and how the genre-characteristic functions of reviewing are fulfilled. The following questions are addressed: 1) Imagery: Instagram primarily being a visual medium, how do review posts typically make use of the visual affordances of the platform? 2) Textual conventions: how do review posts typically make use of the textual affordances and apply the textual conventions of the review genre? 3) Media formats: more generally, how are the perceived affordances of the platform and genre used for reviewing purposes? 4) Strategies: how do the Instagram book reviewers typically seem to align reviewing to their agenda, and what do they claim for their primary intentions for making reviews of books on Instagram?

A multi-method and mixed-data design was adopted to answer these questions. The analysis was divided into two phases: first, a macro outline of \#bookreview posts, to capture the size and some general features of the global community, and second, a micro analysis of a local sample, to examine more deeply the genre characteristics. After the analysis of the coded local sample, findings from the global community are incorporated as complementary exploratory observations to supplement the findings.

\section{Data and method}

The analysis covers public entries that are more permanent, that is they are not 'stories' - a feature launched in August 2016, where entries are available on the user's profile for only 24 hours. To collect the posts that were published on Instagram and provided with the given hashtag at a given point of time, the open software Instagram Scraper was used. This is an application written in Python that 'scrapes' and downloads Instagram users' photos and videos (http://github.com/rarcega/instagramscraper; see also Caliandro and Candini 2017).

To enable the retrieval of individual users and relevant information regarding the book-review posts, the script was enhanced by additional features, and the new script was released online (anonymized). The script transferred the internal user-id to a user name and retrieved these users' metadata, which included user name, URL address of the post, caption, number of likes and comments per post, number of followers and users followed by a user, user handle ('bio') 
and rank of the hashtag \#bookreview. The data retrieval occurred from 25 to 29 January 2019 (Instagram Scraper) and from 30 January to 3 February 2019 (enhanced script).

For the macro analysis, the script retrieved 631,771 posts in which the hashtag \#bookreview was used, from 199,568 unique users. Among these posts, we do not know for what purpose the hashtag was used, whether it was a reference to a book review published in traditional media, written by a professional reviewer, or whether the user was writing about book reviews in general, or perhaps happened to use \#bookreview for promotion or spam. With such large amounts of data, it is impossible to sort out the original review posts, which should be conducted by manual coding, as the review cannot be reduced to some formalized characteristics. Therefore, the macro analysis could only address some formal characteristics of the use of the hashtag.

For the micro analysis, an initial sample of a local community was chosen by focusing on a geographically and culturally limited area of one country and a relatively small community of Finnish-speaking Finland, where there are 4.9 millions of native speakers of the Finnish language, it was possible to get a comprehensive understanding of the local Kirjagram community that reflects and circulates the ideas of the global Bookstagram community. The data consists of entries from a Finnish book reviewing community, in which the entries were hashtagged with \#kirjaarvostelu ('book review') at the point of the data collection. The hashtag corresponds, for example, to \#bokrecension (7,530 entries), \#boganmeldelse (4,699 entries), \#buchrezension (8,268 entries), \#critiquedelivre (336 entries) and \#recensionelibri (9,645 entries) in other language communities.

The data collection occurred on 27-29 December 2018. There were 645 posts tagged with \#kirjaarvostelu. Entries were collected and analysed by opening each image and using the entire post as a unit of analysis. Because the community was included in its entity, personalisation of the feed did not significantly influence the results.

To analyse the data, the method of applied thematic analysis was used (Guest et al., 2012). To gain an overview, 25 per cent - 160 entries in total, from 65 users - of the Finnish bookreview space with \#kirjaarvostelu were allotted to a category that was developed from within the contents. The coding occurred on 31 December 2018 and 3-4 January 2019. A quarter of the whole population was assessed as a saturated sample, as the rest of the material of the entire community was browsed through and did not show any further deviations from the coded material.

The micro analysis was complemented with deviating cases from the global reviewing community. The identification of atypical cases followed the method of deviant case sampling, in which the sampling includes cases that are unusual and anomalist with regard to the particular dimension of interest (Bryman 2016).

\section{Outlining the \#bookreview community: macro characteristics}

Among the 199,568 unique users, 1,381 (0.2 \%) had set their profile as private, which disabled access to some parts of their data (the content of the post and the number of followers/following). With the majority $(\mathrm{N}=198,187)$ being public, though, the genre of review appears to be very community- and network-oriented. To minimize the number of fake 
or irrelevant entries, the dataset was further limited by excluding posts based on the following interaction criteria: likes $\leq 5$, followed $\leq 20$, following $=0$. This way, the data was limited to 594,804 posts in total, all public entries, by 65,534 individual users. When, further, users with $\leq 10$ posts in their account were eliminated - many of them still featuring spam or irrelevant topics and indicating no continuity which would be elementary to the reviewing - the number of posts was reduced to 163,269 entries and the number of users 8,474 individual users. The central dimensions of this dataset are gathered in Table 1 . In total, 1,907 posts (1\%) were video posts and 161,362 (99 \%) still images.

\begin{tabular}{|l|l|l|}
\hline & Average & Range \\
\hline All posts by reviewers & $1,061.6$ & $11-100,003$ \\
\hline Review posts & 19.3 & $1-2,508$ \\
\hline Followers & $1,376.3$ & $21-236,597$ \\
\hline Following & 917.3 & $1-7,509$ \\
\hline Comments & 3.3 & $0-1923$ \\
\hline Likes & 61.7 & $6-10,092$ \\
\hline
\end{tabular}

${ }^{1}$ Followers and following are user-related dimensions ( $N=8,474$ book reviewers), while comments, likes and videos are related to the individual posts ( $N=163,269$ book review entries).

Table 1. Central dimensions of the Instagram book reviewing community in the data.

When examined in terms of one single variable (number of posts, followed users, following users and most-liked posts), the lists of 'top book reviewers' may look very different. While posting frequency does not indicate relevance or influence, and a high number of comments is typically a sign of a campaign or competition organized for the followers (e.g., giveaways), the number of followers and likes indicate attention. Tables $2 \mathrm{a}$ and $2 \mathrm{~b}$ present a multivariable list of 20 Instagram book reviewers in terms of their attention and influence. Table 2a is a production-driven presentation, featuring the most frequently posting users, while Table $2 b$ puts forward an audience-driven presentation, showing the user reviewers with the largest audiences (the highest number of followers) and the most intensive audience interaction (the highest number of likes and comments).

[TABLES 2a AND 2b are at the end of the article]

As indicated in the tables, many of the top reviewers appear to be book bloggers or vloggers, engaged public readers or online book communities with review function. The reviewing activity was typically accompanied by other book-related community markers, such as \#bookworm, \#booklove, \#bookaholic, \#bookobsessed and \#igbooks, and a number of linguistic derivatives. Further observations from the dataset will be incorporated into the analysis of the local \#kirjaarvostelu community.

\section{Initial analysis: basic features of local reviews}

It was found that all the reviews fitted into two main categories: textual reviews ( $N=103,64$ $\%)$ and metacoverage regarding book reviews ( $N=57,36 \%)$, to be discussed in this section. Congruent with the material of the global sample, the posts of the coded local sample originated from three main types of profiles: online content creators ( $\mathrm{N}=33$ posts, $21 \%)$, hobbyists or experts reviewing books ( $\mathrm{N}=23,14 \%)$ and the book enthusiasts or 'ordinary 
readers' ( $\mathrm{N}=104,65$, \%). Online content creators (e.g., book bloggers and podcasters) used Instagram as one of their platforms to spread messages and connect with like-minded users. Hobbyists were anchored in a special area of interest (e.g., cooking, knitting, sports), accidentally applying the genre of review. The core of the original Instagram reviewers were the book enthusiasts, who set goals for themselves to read a certain number of books and used Instagram as their reading journal.

While the two first groups of users were more professional, with regular updates, affiliate partnerships and an ambition to reach a wide audience, the enthusiasts group did not make claims for being anything other than ordinary readers, or 'book lovers'. This group also tended to include younger users, between the ages of 14 and 20. The youngest book audiences were covered by parents evaluating children's literature. Therefore, the phenomenon of book reviewing can be seen to comprise a population with a wide age range.

\section{Textual reviews}

Instagram being a visual medium designed for mobile use, the space for written text is limited. The written texts are designed to be captions to assist the visual images, and their maximal length is limited to 2,200 characters. In the public display mode, texts are additionally truncated after 125 characters, and the reader needs to click 'more' to see the rest of the text. There are also other features that make the writing of texts far from user friendly. The interface for writing texts is limited, occupying less than half of the mobile screen in the edit mode. Paragraphs have to be separated with the help of punctuation marks or symbols. Also, links are not supported in the body text, which means that they are often attached to the bio or omitted.

Despite these major restrictions for written text, many of the Instagram reviews had a primary focus on text. The image typically presented the book cover, possibly with carefully designed accessories. These textual reviews seemed to resist the platform policy by intentionally misinterpreting the caption norm and turning the written text into the primary mode of communication. However, the literary review has always to a great extent leant on written communication, where the focus is on verbal expression of an aesthetic encounter and its interpretation and elucidation, with a pronunciation of an aesthetic judgement and an argument for this judgement (Orlik 2016). The literary discourse allowed even experimentation, such as in the account @7wordbookreview drawing on Instagram's short format and producing aphorism-like seven-word judgements, rounded off with numeric rating. Within the texts, some reviewers were using a star rating or numeric system, which they even clarified in a specific entry, delivering a written description for every level of assessment. In addition to numbers (1-5 or 1-10), some used emojis, such as stars, flowers or animal faces.

While the text presented a description of the book with a rating, the images focused on quite a limited number of carefully selected details - coffee or tea cups, food, flowers. Alternatively, the books were located in intimate settings, such as beds, sofas or cosy corners at home, featuring bed linen, blankets, rugs, carpets, earphones, laptops and home decorations. Other books were photographed when the reviewer was on vacation and featured a beach or summer cottage in the background. The details often related to the topic of the book; for example, cooking books would be accompanied by a relevant food display. Some of the reviewers used specific items to create continuity; for example, one user photographed a teddy bear in attachment to each book cover image and also used teddy bear-face emojis in his ratings. 
The images were indexical in their nature; they provided hints of a human presence but very rarely exposed the reviewer in the pictures or showed physical spaces in their entity. Posts focusing on the reviewer instead of the book reviewed were typically separated from the review contents by hashtags such as \#meetthebookstagrammer or \#currentlyreadingselfie. This disembodied form of reviewing is basically a continuation of the classical review tradition, in which the reviewer builds a profile through textual representations. In the selfiesaturated culture, it is, however, noteworthy that one form of expression in such a systematic way avoids the representation of persons. The systematic dissolvement of the reviewer's person highlights the focus on book content.

A common reason for book reviewing on Instagram seemed to be because the users 'didn't have the energy to create a real blog' (@kirjablogi). Also, rather than aspiring to establish a 'micro-medium' for reviewing, many of the reviewers were involved in book-reading challenges, and the reviews marked the break points in the process of this personal engagement.

\section{Metacoverage of reviews}

As mentioned previously, 36 per cent $(\mathrm{N}=57)$ of the local sample $(\mathrm{N}=160)$ were categorized as metacoverage. Metacoverage means that the content refers to a book review published somewhere other than on Instagram. The following forms of metacoverage were identified:

- Mentions of reviews published elsewhere ( $\mathrm{N}=40,70 \%)$ : references to content published, for example, on Goodreads, or in individual book blogs, podcasts or vlogs.

- Shortened reviews ( $\mathrm{N}=9,16 \%)$ : truncated or short versions of full reviews that were published elsewhere. Most of the producers added metatext or appropriate hashtags to signalize that the full version of the review is in the primary publication venue, but some did not, relying on the reader to be knowledgeable about the YouTube channel or book blog, the link to which was attached to the bio.

- Teasers ( $\mathrm{N}=4,7 \%)$ : descriptions or sneak peeks of upcoming reviews that may be published on Instagram or other platforms.

- Contextual posts ( $\mathrm{N}=4,7 \%)$ : accounts concerning the production of reviews; clarification of the evaluation criteria; glimpses into the process of reading and initial thoughts about a book under process; description of reading goals; and wrap-ups of reading activities within a certain period, usually monthly or annually.

According to a strict definition, the authors of these posts were not original-content creators, placing their primary content in blogs or vlogs and using Instagram posts only for connecting to potential audiences or peers. In this respect, it can be said that a considerable amount of \#bookreview material on Instagram is actually supportive material rather than original reviews. For many users, the primary motivation for using Instagram for review coverage is to drive traffic to the original contents.

\section{Complementary analysis: additional features}

The majority of Instagram reviews at both local and global level were very homogeneous, making use of written text and images of book covers. There were also some uses of video, visuality and interaction, but they were not common. Through complementary exploration of the global community for picking up visually deviant cases for closer analysis, three more 
categories of Instagram reviews were identified: video reviews, reviews with visual effects and facilitated or participatory reviews.

\section{Video reviews}

Instagram launched video sharing in June 2013. In the beginning, the length was restricted to 15 seconds, and in 2016, it was extended to 60 seconds. Since the review format typically requires in-depth analysis and argumentation and leans upon a logocentric tradition, the application of the moving image, in particular the very limited length, requires innovative solutions to be used.

A typical example is The One Minute Book Review (@oneminutebookreview), an account driven by Aun Abdi, a vlogger who describes himself as a 'level 2 personal trainer and wannabe accountant'. He started his Instagram video reviews in March 2018, simultaneously running a YouTube channel. Another example of uses of video was Kaitlyn Walker (@ktxx22), who used a hashtag of her own to tag the video reviews, \#ktxx22reviews, and published her first Instagram book-review video in March 2017. She called the one-minute reviews 'book bursts', inspired by a vlogger called Family Food Dude who had developed a format on YouTube for reviewing ice cream and junk food.

Both these video-review examples make use of the vlogging format, in which a talking head looks straight into the camera. Other options in video reviews included browsing through the book, showing the book in movement or in special lighting, or showing video on the original review text being scrolled on the screen, assisted by an accompanying text.

\section{Reviews with visual effects}

As established, the normative image in book reviews was the book cover, and the imagery was to a high degree photography-centric. Only a very limited number of images attached to book reviews were other than photographs with the book cover. Some images attached to the contexts of book reading showed the reviewer reading or walking and holding an open book, or constellations of books as physical artefacts, but these images were much more typical of the non-review part of the Bookstagram community. The visual experimentation with drawn images, illustrations, infographics or any other kind of visual development building upon the literary content or reading experience was very scarce.

However, some of the reviewers within the global Bookstagram community did develop the visual dimension of the reviews further. The account Book Reviews Sketches (@bookreviewsketches), launched in May 2018 to address one book a day, with an initial goal to read and review 100 books, featured in attachment to short written reviews book covers drawn with the finger on a mobile app by a UK-based reviewer. In attachment to the written reviews, the user also took up questions of the day (QOTD), addressing her bookreading habits and preferences beyond the actual book reviews. Like many other Bookstagrammers, this user had previously been tracking her reading activity on Goodreads, and, in her own words, 'I had considered starting a blog, but that seemed like a lot of work to set up so I started an Instagram account to keep it separate from my personal one.' (Personal communication, January 10, 2019.)

Some review accounts made posts where the text, or part of it, was placed to the image. Alternatively, this poster-like image could contain the bottom line similar to a blurb. Even in 
these kinds of images the book cover was considered important and included in the picture. One user (@rae.reads.books) posted quotes from books she was reading, captured as photographs straight from the book.

\section{Facilitated or participatory reviews}

One more form that can be identified in the global review sphere are reviews that need a facilitator to come into being. These facilitated or participatory reviews constitute a form of Instagram reviews that display images with people more often than the other forms of book reviews.

Perhaps the most eminent example of these kind of reviews is The Subway Book Review (@subwaybookreview), a 'social media project' by German-born culture writer Uli Beutter Cohen. Started in 2013 in the New York City subway, the project had contributors in, for example, Washington DC, Mexico City, London, Berlin, Milan, Barcelona and Sydney. It operated through crowdfunding and had also developed into a blog-based online presence (Bausells 2015). The main idea was asking strangers in public places what they were reading; this format was followed in other domains of arts and culture, as well, for example Your Soundtracks (@yoursoundtracks) in music, as well as in the human-interest story-based form of listening to peoples life destinies in Humans of New York (@humansofny). In November 2018, the project introduced a subproject for children, the Subway Book Review for Kids (@subwaybookreviewforkids). All these facilitated reviews presented a more journalistic approach to covering literature. Their method was the basic journalistic interview, through which a literary voice was re-constructed and the reading experience narrated by the facilitator, that is other than the actual reader of the book.

Another case of giving-a-voice practice was the account Father Reading Every Day (@fatherreading), which featured metacoverage of a father and his three-year-old child reading a bedtime story, gathered under the hashtags \#FRED and \#fatherreading. On their blog page (https://fatherreading.wordpress.com), the father wrote that he was a primary school teacher who recognized the importance of reading and wanted to inspire other fathers to read with their children. Started in 2018, the blog included longer written posts and videos, while the Instagram posts were often shortened reviews or mentions of the actual published reviews.

The forms of participation that engage the majority of users are the book reading and reviewing campaigns: readathons and book challenges. They were a prolific form of engagement and interaction on Instagram, but they often originated from other platforms, such as Goodreads. The campaigns were typically initiated by libraries, associations or private users, and their connection to the specific genre of review was loose. One specific way of organising social interaction from the bottom-up was 'buddy reading' (BR), a convention from Goodreads that refers to an arrangement in which two or more individuals come together to set up common reading objectives - for example, a reading schedule with some break points to discuss the content - and thus share the reading experience. This arrangement varied from very structured ways of conduct, for which some Goodreads groups even had written instructions, to more informal ways of interaction that were not formally led or moderated (see e.g. NBRC 2013). On Instagram, by setting up a buddy read, a user could invite others to the process, and by using a common hashtag followers were able to keep track on the process. The buddy reads, however, typically appeared to result in individual reviews instead of 
collectively elaborated or dialogical contributions. Still, audiences could benefit from the outcome by being able to read different opinions and experiences related to the selected book.

Finally, the most structured communities were the paid book review services set up for new and self-publishing authors for marketing, the so-called ARC (Advance Review/Reading Copy) services. Examples include Candid Book Reviews (@candidbreviews) and Hidden Gems Books (@hgbooks). ARCs are given to readers in advance of the book launch with the hope that they choose to review the book as soon as it is released. The review services often collaborate with Amazon, and Instagram was yet another channel for them to reach audiences.

\section{Discussion}

When it comes to the perceived affordances of platform and genre, a number of observations are worth being emphasized. First, the Instagram reviews present a short format for individualized participation that aims at addressing one's reading experiences concerning a specific book. Reviews are more typically to be considered as recommendations or suggestions based on a reading experience that is alleged to be individual, idiosyncratic and unique, instead of in-depth analyses with generalizable observations concerning a specific (sub)field of literature. Reviewing is connected to self-improvement rather than improvement of literature. Reviews are thus equally, if not more, important for their creators, and making personal reading engagement visible is the key. As reflected in the sports-inspired term 'readathons', reviews often function as break points of a reading marathon, with personal goals set, typically measured by the number of books to be read within a period of a year or a month. Review entries can thus be understood as book-reading accomplishments, where a central objective is to create a public image of oneself as a reading person. This creation of a 'reading self' (Goffman 1990) is based on systematically performing cultural engagement online and taking care of its impression management in a public space and is intended to be seen as such by others. Reporting the accumulated results of this 'reading sport' makes it more meaningful and helps assess one's identity and capabilities as a cultural consumer or citizen.

Second, the analysis confirms the fact that the vernacular reviewers on Instagram are closer to the reading audiences than are the institutionalized reviewers. While institutionalized reviewers position themselves in between the primary production of literature and the audience, the vernacular reviewers declare themselves part of the audience, benefiting from the primary production and giving direct feedback to it but not seeking an independent position between these two. The reviewing is, therefore, not attached to a framework inbuilt in the professional reviewing, which dedicates special attention to localising a specific work in a history and tradition, or to its production context (Orlik 2016). The vernacular Instagram reviewers are not so much re-viewers, retrospectively looking back at a carefully selected published piece of work to place it in a larger sociocultural and historical context, as meviewers, individualized experts of their own reading experience, mediating their intellectual, emotional and aesthetic ephemeral experience regarding the book product they happen to have received or stumbled upon. While the context for re-viewers is (the production of) literature, the context for me-reviewers is book culture, or reading culture. Both of these groups of producers are public receivers of literature, but re-viewers relate this public reception to the production and me-viewers to the consumption paradigm.

The Instagram reviewers are more directed towards peer-to-peer mediation, or shared coconsumption, than judgement of books. They constitute a prosumers' (producing consumers') 
community of reading practice aimed at promoting the lifestyle of reading in the supportive 'affinity space' (Hayes and Gee 2010). As this mediation stays in the same community where it originated, I have called it 'cultural intramediation' rather than intermediation (AUTHOR 2018). By using representations of one's reading self, an individual is able to make multiple connections to the imagined community that is doing similar things, simultaneously creating and strengthening this community. Encouragement and mutual empowerment between the users builds open literary pedagogies. By opening up their reading processes online, users intend to help others in choosing and evaluating literature. In Instagram reviews, the judgemental character of the review is softened or downplayed by using related hashtags, such as \#booksuggestion and \#bookrecommendation. In this respect, as textual representations, the Instagram reviews are to be understood rather as contingent manifestations of relatively long-lasting participatory practices (see also Bruns 2008) or part of an ongoing process of participation in the social life of fan communities or scenes (see also Ito 2010) than media or literary works designed to stand on their own, apart from their social and cultural context.

Last, but not least, the reviews on Instagram include uses of affordances that counteract the platform strategies. With regard to the fact that Instagram is designed for visual representations, it is striking that the reviews are at large relatively conventional in their visual imagery, putting more emphasis on their textual content than the visual innovation of expression. Despite restrictions for writing, the written text continues playing a central role, the atmosphere, featured in very structured and similar ways, being the most central input and added value of the images. Instagram also restricts outbound traffic by not allowing in-text links, but at least a third of the review contents were classified as metacoverage referring to original content that is published beyond the app. Users intend to use Instagram for increased visibility and connectivity, or to drive traffic to original content, rather than producing original content within the app. Rather than pushing the genre conventions by more powerfully using the possibilities of new media within the app, Instagram appears to be a mixed-media or crossroads platform that endorses close ties with other platforms. The 'bounce' or 'junction' function supports (textual) presentation and argumentation in the long format of blogs and vlogs.

Finally, the online-native formats such as video reviews are still very young. In the advent of the blogosphere, weblogs were typically characterized as reading journals or online diaries (Steiner 2010). Since then, they have shown degrees of institutionalisation or professionalisation (Kim 2012, Leadbeater and Miller 2004). It might be that at the point in time of the analysis, the \#bookreview niche on Instagram has not yet developed into a fully independent way of expression but lives from the co-existence with other platforms, discourses and genres. It is also likely that new development will unfold rapidly. The features and terms and conditions of use of a social networking platform may also change abruptly, as shown by the Cambridge Analytica case that made Facebook to accelerate the curtailment of its API for non-commercial partners (Bruns 2018).

\section{Conclusion}

Positioned at the consumption end of the cultural production paradigm, vernacular book reviews are not challenging or replacing the longer book-review format, especially not the institutionalized professional book review. Rather, the vernacular reviews mark diversification and democratisation in the review sphere - diversification by introducing new, more processual and participatory practices for reviewing and democratisation by enabling 
users of different degrees of expertise and agency to be involved in the public communication.

The study documented findings at a point in time when 'instareviewing' was still in its infancy. Longitudinal analyses of the online genre trajectories are important to outline a historical perspective for the turbulent evolvement in cultural communication and online engagement and to achieve more general perspectives on cultural and digital citizenship.

The analysis indicates that the amateur paradigm of cultural critique needs to be further elaborated into a theoretically more nuanced field of research, locating it closer to the consumption and learning paradigms. While the institutionalized domain of reviewing puts great emphasis on the reviewer's role and legitimacy when delivering judgements, in the vernacular domain of reviewing, the focus seems to be on collective learning processes to create critical communicative agency as part of reflexive consumption.

\section{References}

Abidin, C. (2017), ‘\#Familygoals: Family influencers, calibrated amateurism, and justifying young digital labour', Social Media + Society, 3: 2, pp. 1-15.

AUTHOR (2018).

AUTHOR (2019, forthcoming).

Bausells, M. (2015), 'Subway book review glimpses the lives of New Yorkers via the books they read' The Guardian, October 5, 2015, https://www.theguardian.com/books/2015/oct/05/subway-book-review-glimpses-thelives-of-new-yorkers-via-the-books-they-read. Accessed 8 January 2019.

Blank, G. (2007), Critics, ratings, and society: The sociology of reviews. Lanham: Rowman \& Littlefield Publishers.

Bolin, G. (2011), Value and the media: Cultural production and consumption in digital markets. London and New York: Routledge.

Boot, P. (2011), 'Towards a genre analysis of online book discussion: Socializing, participation and publication in the Dutch booksphere', Selected Papers of Internet Research. Chicago: Association of Internet Researchers (AoIR).

Bruns, A. (2018), 'Facebook shuts the gate after the horse has bolted, and hurts real research in the process', Internet Policy Review, https://policyreview.info/articles/news/facebook-shuts-gate-after-horse-has-bolted-andhurts-real-research-process/786. Accessed 8 June 2018.

Bryman, A. (2016), Social research methods. 5th ed. Oxford: Oxford University Press.

Caliandro, A. and Candini, A. (2017), Qualitative research in digital environments: A research toolkit. London: Routledge.

Couldry, N, Livingstone, S. and Markham, T. (2010), Media consumption and public engagement: Beyond the presumption of attention. London: Palgrave MacMillan.

Curran, J. and Morley D. (eds) (2006), Media and cultural theory. Abingdon and New York: Routledge.

Domsch, S. (2009), 'Critical genres: Generic changes of literary criticism in computermediated communication', in J. Giltrow and D. Stein (eds.) Genres in the Internet: Issues in the theory of genre. Amsterdam: John Benjamins Publishing Company, pp. 221-38.

Frey, M. and Sayad, C. (eds.) (2015), Film criticism in the digital age. New Brunswick: Rutgers University Press. 
Gibbs, M., Meese, J., Arnold, M., Nansen, B. and Carter, M. (2015), '\#Funeral and Instagram: Death, social media, and platform vernacular.' Information, Communication \& Society, 18: 3, pp. 255-268.

Gibson, J.J. (1979), The ecological approach to visual perception. Boston: Houghton Mifflin. Giltrow, J. and Stein, D. (eds.) (2009), Genres in the Internet: Issues in the theory of genre. Amsterdam: John Benjamins Publishing Company.

Goffman, E. (1990), The presentation of self in everyday life. London: Penguin.

Grafton, K. (2010), Paying attention to public readers of Canadian literature: Popular genre systems, publics, and canons. Vancouver: University of British Columbia.

Guest, G., MacQueen, K.M. and Namey, E.E. (2012), Applied thematic analysis. London: Sage Publications.

NBRC, Nothing but reading challenges (2013), 'What is buddy read? How does it work?', Goodreads, May 19, 2013, https://www.goodreads.com/topic/show/1333468-what-is-abuddy-read-how-does-it-work. Accessed 8 January 2019.

Hayes, E.R. and Gee, J.R. (2010), 'Public pedagogy through video games: Design, resources, and affinity spaces', In J.A. Sandlin, B.D. Schultz and J. Burdick (eds.) Handbook of public pedagogy: Education and learning beyond schooling. New York: Routledge, pp. 116-124.

Hohendahl, P.U. (1982), The institution of criticism. Ithaca: Cornell University Press.

Ito, M. (2010), 'The rewards of non-commercial production: Distinctions and status in the anime music video scene. First Monday, 15: 5.

Jenkins, H. (2006), Convergence culture: Where old and new media collide. New York: New York University Press.

Kammer, A. (2015), 'Post-industrial cultural criticism: The everyday amateur expert and the online cultural public sphere', Journalism Practice, 9: 6, pp. 872-889.

Kim, J. (2012), 'The institutionalization of YouTube: From user-generated content to professionally generated content', Media, Culture \& Society, 34: 1, pp. 53-67.

Kristensen, N.N. and From, U. (2017), 'From ivory tower to cross-media personas: The heterogeneous cultural critic in the media. In N.N. Kristensen and U. From (eds.), Cultural journalism and cultural critique in the media. Abingdon: Routledge, pp. 94112.

Leadbeater, C. and Miller, P. (2004), The Pro-am revolution. London: Demoso.

McWhirther, A. (2016), Film criticism and digital cultures: Journalism, social media and the democratization of opinion. London: IB Tauris.

Miller, C.R. and Shepherd, D. (2009), 'Questions for genre theory from the blogosphere', In J. Giltrow and D. Stein (eds.), Genres in the Internet: Issues in the theory of genre. Amsterdam: John Benjamins Publishing Company, pp. 263-290.

Naseem, F. (2018), 'Bookstagram for Beginners!', The Guy with the Book, May 17, 2018, http://theguywiththebook.com/2018/05/17/bookstagram-for-beginners. Accessed 8 January 2019.

Nicoll, B. and Nansen, B. (2018), 'Mimetic production in YouTube toy unboxing videos', Social Media + Society, 3, pp. 1-12.

Norman, D.A. (1999), 'Affordance, conventions, and design', Interactions 6: 3, pp. 38-42.

Orlik, P.B. (2016), Media criticism in a digital age: Professional and consumer considerations. London: Taylor \& Francis.

Schwemmer, C. and Ziewiecki, S. (2018), 'Social media sellout: The increasing role of product promotion on YouTube', Social Media + Society, 4: 3, First Published August 14, 2018. 
Smith, A. and Anderson, M. (2018), 'Social media use in 2018', Pew Research Center, March 1, 2018, http://www.pewinternet.org/2018/03/01/social-media-use-in-2018/. Accessed 6 December 2018.

Steiner, A. (2008), 'Private criticism in the public space: Personal writing on literature in readers' reviews on Amazon', Participations, 5: 2.

Steiner, A. (2010), 'Personal readings and public texts: Book blogs and online writing about literature', Culture Unbound, 2: 2, pp. 471-494.

Toffler, A. (1980), The third wave. London: Collins.

Verboord, M. (2010), 'The legitimacy of book critics in the age of the Internet and omnivorousness: Expert critics, Internet critics and peer critics in Flanders and the Netherlands', European Sociological Review, 26: 6, pp. 623-637.

WordStream (2017), '33 mind-boggling Instagram stats \& facts for 2018', https://www.wordstream.com/blog/ws/2017/04/20/instagram-statistics. Accessed 12 December 2018. 


\begin{tabular}{|c|c|c|c|c|c|c|c|}
\hline Username & Category & Country & $\mathrm{N}$ of reviews & $\begin{array}{l}\mathrm{N} \text { of } \\
\text { posts } \\
\text { in } \\
\text { total }\end{array}$ & $\begin{array}{l}\mathrm{N} \text { of } \\
\text { followers }\end{array}$ & $\begin{array}{l}\text { Average } \mathrm{N} \\
\text { of } \\
\text { comments } \\
\text { to reviews }\end{array}$ & $\begin{array}{l}\text { Average } \mathrm{N} \\
\text { of likes to } \\
\text { reviews }\end{array}$ \\
\hline $\begin{array}{l}\text { New Adult E Dintorni } \\
\text { @newadultedintorniblog }\end{array}$ & Blogger & Italy & 885 (35 \%) & 2,501 & 1,557 & 0.3 & 36.8 \\
\hline $\begin{array}{l}\text { Baker Street Shelves } \\
\text { @bakerstshelves }\end{array}$ & Reader & UK & $859(39 \%)$ & 2,181 & 816 & 1.1 & 43.5 \\
\hline $\begin{array}{l}\text { Ari Stone } \\
@ \text { candidbreviews }\end{array}$ & Community & USA & $649(25 \%)$ & 2,614 & 157 & 0.2 & 8.4 \\
\hline $\begin{array}{l}\text { Ana's Attic Book Blog } \\
\text { @anasatticblog }\end{array}$ & Blogger & USA & $624(26 \%)$ & 2,415 & 8,739 & 2.4 & 40.0 \\
\hline $\begin{array}{l}\text { EDGy Reviews } \\
\text { @edgyreviews }\end{array}$ & Community & USA & $521(49 \%)$ & 1,062 & 682 & 0.8 & 19.2 \\
\hline $\begin{array}{l}\text { Minx } \\
\text { @thegenreminxbookreviews }\end{array}$ & Blogger & USA & 403 (57\%) & 710 & 247 & 0.7 & 10.9 \\
\hline $\begin{array}{l}\text { Rizky Mirgawati } \\
@ \text { @rizkymirgawati }\end{array}$ & Blogger & Indonesia & 400 (17\%) & 2,383 & 7,100 & 3.7 & 65.4 \\
\hline $\begin{array}{l}\text { Hidden Gems Books } \\
\text { @hgbooks }\end{array}$ & Community & USA & $380(31 \%)$ & 1,216 & 514 & 1.0 & 8.3 \\
\hline $\begin{array}{l}\text { Deborah Stevenson } \\
\text { @runningrara }\end{array}$ & Blogger & USA & $380(10 \%)$ & 3,917 & 1,129 & 5.4 & 94.1 \\
\hline $\begin{array}{l}\text { Bambi Unbridled } \\
\text { @bambi_unbridled }\end{array}$ & Blogger & USA & $375(43 \%)$ & 866 & 390 & 0.6 & 10.9 \\
\hline $\begin{array}{l}\text { Lulu's Vintage } \\
\text { @lulualamode }\end{array}$ & Blogger & USA & $349(57 \%)$ & 609 & 263 & 0.8 & 14.7 \\
\hline $\begin{array}{l}\text { Búho } \\
\text { @buhosbookreview }\end{array}$ & Blogger & Nicaragua & $345(44 \%)$ & 779 & 495 & 0.7 & 33.0 \\
\hline $\begin{array}{l}\text { Just A Girl \& Her Books } \\
\text { @lauras_book_addiction }\end{array}$ & Reader & UK & $335(3 \%)$ & 10,000 & 6,223 & 2.7 & 45.3 \\
\hline $\begin{array}{l}\text { Books\&Sweets } \\
\text { @books_sweets }\end{array}$ & Blogger & Croatia & 315 (45 \%) & 707 & 1,606 & 2.7 & 112.6 \\
\hline $\begin{array}{l}\text { Kim B. } \\
\text { @kimberlyfayereads }\end{array}$ & Reader & USA & $294(10 \%)$ & 3,274 & 2,939 & 2.6 & 44.8 \\
\hline $\begin{array}{l}\text { Helen } \\
@ \text { whathelsreadnext }\end{array}$ & Reader & Sweden/UK & 290 (67\%) & 436 & 240 & 0.8 & 15.4 \\
\hline $\begin{array}{l}\text { Rae } \\
@ \text { @rae.reads.books }\end{array}$ & Reader & N.A. & $284(52 \%)$ & 541 & 93 & 0.2 & 10.7 \\
\hline $\begin{array}{l}\text { Geramie Kate Barker } \\
\text { @gemsbooknook }\end{array}$ & Blogger & Australia & $269(40 \%)$ & 676 & 129 & 2.8 & 53.4 \\
\hline $\begin{array}{l}\text { Barbara Pitanti } \\
\text { @barpit }\end{array}$ & Blogger & Italy & $265(36 \%)$ & 734 & 311 & 0.8 & 19.9 \\
\hline $\begin{array}{l}\text { Juliette Frye } \\
\text { @bookish.juju }\end{array}$ & Reader & \begin{tabular}{|l|} 
USA/ \\
France \\
\end{tabular} & 247 (55 \%) & 451 & 370 & 0.7 & 35.2 \\
\hline
\end{tabular}

Table 2a. The 20 book reviewers on Instagram with the highest review posting frequency. 


\begin{tabular}{|c|c|c|c|c|c|c|c|}
\hline Username & Category & Country & $\begin{array}{l}\mathrm{N} \text { of reviews } \\
\text { in data }\end{array}$ & $\begin{array}{l}\mathrm{N} \text { of } \\
\text { posts } \\
\text { in } \\
\text { total }\end{array}$ & $\begin{array}{l}\mathrm{N} \text { of } \\
\text { followers }\end{array}$ & $\begin{array}{l}\text { Average } \mathrm{N} \\
\text { of } \\
\text { comments } \\
\text { to reviews }\end{array}$ & $\begin{array}{l}\text { Average } \mathrm{N} \\
\text { of likes to } \\
\text { reviews }\end{array}$ \\
\hline $\begin{array}{l}\text { Bill } \\
\text { @kenyan_library }\end{array}$ & Blogger & Kenya & $22(4 \%)$ & 555 & 13,817 & 4.3 & 85.4 \\
\hline $\begin{array}{l}\text { Coconut Books } \\
\text { @coconutbooks }\end{array}$ & Blogger & Indonesia & $13(1 \%)$ & 2,069 & 77,246 & 40.0 & 1549.0 \\
\hline $\begin{array}{l}\text { Reading Women } \\
\text { @thereadingwomen }\end{array}$ & Podcaster & USA & $64(7 \%)$ & 873 & 102,413 & 5.0 & 100.2 \\
\hline $\begin{array}{l}\text { Nel } \\
\text { @bookish_nel }\end{array}$ & Reader & USA & $5(2 \%)$ & 240 & 13,667 & 8.7 & 200.6 \\
\hline $\begin{array}{l}\text { Folded Pages Distillery } \\
\text { @foldedpagesdistillery }\end{array}$ & Blogger & USA & $29(2 \%)$ & 1,268 & 125,147 & 54.7 & 2511.1 \\
\hline $\begin{array}{l}\text { Abbie } \\
\text { @ab_reads }\end{array}$ & Reader & USA & $78(5 \%)$ & 1,733 & 39,169 & 5.0 & 100.9 \\
\hline $\begin{array}{l}\text { Read the Write Act } \\
\text { @readthewriteact }\end{array}$ & Reader & Australia & $88(10 \%)$ & 877 & 17,429 & 3.3 & 62.5 \\
\hline $\begin{array}{l}\text { Sally } \\
@ \text { whatsallyreadnext }\end{array}$ & Blogger & UK & $26(5 \%)$ & 575 & 16,143 & 4.3 & 84.6 \\
\hline $\begin{array}{l}\text { Abura } \\
\text { @lookingforabura }\end{array}$ & Blogger & $\begin{array}{l}\text { United Arab } \\
\text { Emirates }\end{array}$ & $21(1 \%)$ & 1,517 & 55,229 & 30.0 & 947.9 \\
\hline $\begin{array}{l}\text { Amena } \\
\text { @theclubofbooks }\end{array}$ & Reader & UK & 60 (5 \%) & 1,128 & 14,286 & 3.8 & 73.5 \\
\hline $\begin{array}{l}\text { Silke Wadskjær } \\
\text { Mølgaard @silkreads }\end{array}$ & Reader & Denmark & $42(4 \%)$ & 1,169 & 50,821 & 7.3 & 160.4 \\
\hline $\begin{array}{l}\text { Kath } \\
\text { @kath_reads }\end{array}$ & Blogger & Germany & $6(0 \%)$ & 1,392 & 42,974 & 29.3 & 915.7 \\
\hline $\begin{array}{l}\text { Christine } \\
\text { @weereader }\end{array}$ & Reader & UK & $52(4 \%)$ & 1,206 & 32,006 & 12.0 & 293.8 \\
\hline $\begin{array}{l}\text { Meredith Mara } \\
\text { @meredith.mara }\end{array}$ & Reader & South Africa & $13(1 \%)$ & 1,691 & 40,283 & 34.0 & 1301.6 \\
\hline $\begin{array}{l}\text { Jeana } \\
\text { @hotcocoareads }\end{array}$ & Reader & USA & $7(1 \%)$ & 574 & 17,407 & 28.4 & 726.8 \\
\hline $\begin{array}{l}\text { Renée } \\
\text { @somekindofalibrary }\end{array}$ & Blogger & USA & $35(4 \%)$ & 793 & 27,233 & 4.1 & 80.2 \\
\hline $\begin{array}{l}\text { Lisa } \\
\text { @lifeinlit }\end{array}$ & Blogger & USA & $6(0 \%)$ & 3,217 & 81,965 & 35.2 & 1470.7 \\
\hline $\begin{array}{l}\text { Zoe \& Charli } \\
\text { @thestiffs }\end{array}$ & Blogger & UK & $18(1 \%)$ & 1,689 & 43,191 & 5.3 & 103.2 \\
\hline $\begin{array}{l}\text { Jenna } \\
\text { @jennareadsbooks }\end{array}$ & Blogger & USA & $6(1 \%)$ & 432 & 21,356 & 30.5 & 1068.4 \\
\hline $\begin{array}{l}\text { Rivka } \\
\text { @readbyred }\end{array}$ & Reader & N.A. & $155(8 \%)$ & 2,027 & 7,503 & 3.9 & 74.1 \\
\hline
\end{tabular}

Table $2 \mathrm{~b}$. The 20 book reviewers on Instagram with the most followers and most likes per individual review posts. 